\title{
G

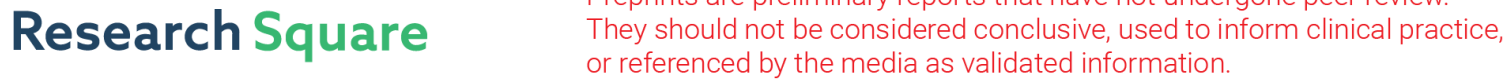 \\ Effects of Grazing Intensity on Soil Nematode Community Structure and Function in Different Soil Layers in a Meadow Steppe
}

\section{Fengjuan Pan}

Northeast Institute of Geography and Agroecology, Chinese Academy of Sciences https://orcid.org/0000-0002-8370-6644

\section{Ruirui Yan ( $\nabla$ yanruirui@caas.cn )}

Institute of Agricultural Resources and Regional Planning, Chinese Academy of Agricultural Sciences

\section{Jinling Zhao}

University of the Chinese Academy of Sciences

\section{Linghao Li}

State Key Laboratory of Vegetation and Environmental Change, Institute of Botany

\section{Yanfeng Hu}

Northeast Institute of Geography and Agroecology, Chinese Academy of Sciences

Ye Jiang

Northeast Institute of Geography and Agroecology, Chinese Academy of Sciences

Jie Shen

Institute of Agricultural Resources and Regional Planning, Chinese Academy of Agricultural Sciences

Neil B. McLaughlin

Ottawa Research and Development Centre, Agriculture and Agri-Food Canada

\section{Dan Zhao}

Canada; Heilongjiang Academy of Agricultural Sciences

\section{Xiaoping Xin}

Institute of Agricultural Resources and Regional Planning, Chinese Academy of Agricultural Sciences

\section{Research Article}

Keywords: community structure, grazing intensity, metabolic footprints, soil nematodes, soil food web

Posted Date: February 22nd, 2021

DOI: https://doi.org/10.21203/rs.3.rs-201553/v1

License: (c) (i) This work is licensed under a Creative Commons Attribution 4.0 International License. Read Full License 
Version of Record: A version of this preprint was published at Plant and Soil on August 18th, 2021. See the published version at https://doi.org/10.1007/s11104-021-05096-4. 


\section{Abstract}

Aims Grazing is a key driver of plant communities and soil functions in grassland ecosystems. Soil nematodes play a vital role in soil ecological functions. however, few studies have explored how grazing shapes soil nematode community in different soil layers.

Methods we investigated the composition, abundance, diversity, metabolic footprint, and food web metrics of soil nematodes over a gradient of grazing in the $0-10 \mathrm{~cm}$ and $10-20 \mathrm{~cm}$ soil layers in a meadow steppe. The relationships between nematode community structure and biotic and abiotic factors were analyzed by principal component analysis (PCA) and structural equation model (SEM) analysis.

Results Light grazing tended to increase the abundance of soil nematodes. Intensive grazing decreased the biomass carbon and metabolic footprints of plant parasites, fungivores, and total soil nematodes in 0-10 cm soils. There was no difference in the biomass carbon and metabolic footprints of soil nematodes among different grazing intensities in the $10-20 \mathrm{~cm}$ soil layer. Soil moisture, aboveground biomass, belowground biomass and Shannon diversity of grass contributed more to changes in soil nematode composition in both soil layers. In the $0-10 \mathrm{~cm}$ soil layer, grazing directly and indirectly affected soil nematode diversity via soil moisture and aboveground biomass, while grazing directly affected soil nematode diversity in $10-20 \mathrm{~cm}$ soil layer.

Conclusions Our results indicate that soil depth can weaken the effect of grazing intensities on soil nematode fauna. Grazing affected the soil nematode community structure via different paths in different soil layers.

\section{Highlights}

- There was less effect of grazing intensity on soil nematode communities at deeper depths

- Grazing affected the soil nematode community via different paths at different soil depths

- Intensive grazing decreased the carbon utilization of soil nematodes

\section{Introduction}

Grasslands are important ecosystems and occupy approximately one-fifth of the land surface in the world (Cao et al. 2019). They assume crucial importance in maintaining biodiversity and combating desertification (Li et al. 2020). Grazing is one of the most common and economical uses of grassland ecosystems. It is well known that herbivore grazing can influence the structure and composition of aboveground ecosystems and can induce potential consequences in belowground ecosystems (Bardgett et al. 1998), such as $\mathrm{C}$ and $\mathrm{N}$ allocation to roots (Hokka et al. 2004; Ilmarinen et al. 2005); additionally, faeces of herbivores can change, affecting the community structure and diversity of soil biota (Bardgett et al. 1998; Wardle et al. 2004). In general, herbivore grazing affects the soil fauna by decreasing or increasing the nutritional quality and quantity of plants or by nutrient return from animal wastes, but 
these nutrients have a heterogeneous spatial distribution (Wang et al. 2006). So far, we know little about the response of soil fauna to grazing in different soil layers.

Soil nematodes are important components of soil ecosystems and are widely used as bioindicators reflecting soil biodiversity and processes in underground ecosystems (Bongers and Bongers 1998). Soil nematodes are assigned to different trophic groups according to their feeding habits, such as plant parasites, bacterivores, fungivores, omnivores and predators (Yeates et al. 1993). They play critical roles in soil ecological processes such as organic matter decomposition and nutrient cycling (Yeates 2003), especially bacterivores and fungivores, which can affect soil ecological processes by regulating the structure and function of bacteria and fungi (Ingham et al. 1985). Plant parasites feeding on plant roots can affect the growth and productivity of plants, and omnivores and predators regulating soil fauna at lower trophic levels in the soil food web are sensitive to external disturbance.

Soil nematode indices can provide insight into the changes in community structure and functions of soil nematodes recovering from disturbance or comparisons among ecosystems (Korthals et al. 2001; Guan et al. 2018). These ecological indices of soil nematodes promote the application of soil nematodes as soil bioindicators. The maturity indices of free-living nematodes (MI) and plant parasites (PPI) are based on the life history traits of individual nematode taxa, and they can reflect changes in soil nematode community structure related to the disturbance of soil ecosystems (Bongers 1990). The enrichment index (EI) and structural index (SI) of the food web provide information about resource availability and the structure or complexity of the soil food web (Ferris et al. 2001). The metabolic footprints of nematodes provide different metrics of ecosystem functions by assessing $\mathrm{C}$ utilization in the soil food web (Ferris 2010). These ecological indices of soil nematodes have been widely used to estimate the soil conditions and structure and function of the soil food web under different ecosystems, such as forestry (Zhang et al. 2015), farmland (Griffiths et al. 2005), and grassland (Hu et al. 2017).

Previous studies have reported that grazing can induce effects on belowground ecosystems by changes in vegetation composition or soil properties (Andriuzzi and Wall 2017). For example, grazing can regulate the linkages between aboveground and belowground parts via direct and indirect shrub effects on nematode abundance (Wang et al. 2018), and can increase the abundance of soil nematodes such as omnivores and predators in a humid grassland (Wang et al. 2006) and fungivores in an arid steppe (Freckman and Huang 1998). The effects of grazing intensity on community structure of soil nematodes are inconsistent. Hu et al. (2015) have found that heavy grazing increased the species richness and abundance of total soil nematodes, but other studies have shown that soil nematodes are more abundant in ungrazed sites or have no response to grazing (Zolda 2006; Andriuzzi and Wall 2017). The contrasting results may be attributed to different grassland ecosystems, as soil nematode composition is known to be highly spatially variable (Rodrigues et al. 2010). More studies in different ecosystems are needed to quantify the grazing effect on the community structure of soil nematodes. Therefore, the response of soil nematode community to grazing intensity in semiarid grasslands can increase our standing of linkages between aboveground and belowground ecosystems. 
In this study, we evaluated the effect of grazing intensity on soil nematode fauna in the $0-10 \mathrm{~cm}$ and 10-20 cm soil layers in a northeast China meadow steppe. We hypothesized that grazing intensity has different effects on the community structure and carbon utilization function of soil nematodes in the 0$10 \mathrm{~cm}$ and $10-20 \mathrm{~cm}$ soil layers and that grazing modifies the soil nematode community via different paths in the two soil layers. The specific objectives of the present study were to 1) determine the effects of grazing intensity on the community structure and metabolic footprint of soil nematodes; 2 ) evaluate the relationship between biotic and abiotic factors and soil nematode community composition in different soil layers; and 3 ) determine the paths by which grazing affects soil nematode fauna in different soil layers.

\section{Materials And Methods}

\section{Experimental site}

The study was conducted at the Hulun Buir Grassland Ecosystem Research Station (HGERS) of the Chinese Academy of Agricultural Sciences (CAAS) (49 $\left.19^{\prime} \mathrm{N}, 119^{\circ} 56^{\prime} \mathrm{E}\right)$ in Hulun Buir, Inner Mongolia, China. The study site has a semiarid continental climate with a mean annual temperature of $-3^{\circ} \mathrm{C}$ and an annual precipitation range of $350 \sim 400 \mathrm{~mm}$. The soil type is defined as kastanozems. The study site is a typical meadow steppe dominated by the natural plant species Leymus chinensis, Stipa baicalensis, Carex duriuscula, Galium verum, Bupleurum scorzonerifolium, and Filifolium sibiricum.

\section{Experimental design}

The grazing experiment was established in 2009 and included six levels of cattle grazing intensity designed in a randomized complete block. All these blocks have been used as summer pastures, beginning in June and ending in September every year. The plots were not grazed from October to May of the following year. Details of the experimental design and management history have been described in a previous study (Xun et al. 2018). Four of the six grazing intensities with 0, 2, 4 and 8 cattle per plot beginning in June, corresponding to $0.00,0.23,0.46$ and $0.92 \mathrm{AU} \mathrm{ha}^{-1}(1 \mathrm{AU}=500 \mathrm{~kg}$ of adult cattle), were selected for the present study, and the grazing intensities were designated G0 (no grazing), G1 (light grazing intensity), G2 (moderate grazing intensity) and G3 (intensive grazing). Soil samples were collected from $0-10 \mathrm{~cm}$ and $10-20 \mathrm{~cm}$ depths with a $10 \mathrm{~cm}$ diameter coring tube in each plot in August 2018. A total of 25 samples were collected from each plot, and all soil samples were sieved and mixed well by hand. Soils used to measure soil properties were air-dried, and soils used to determine soil nematode diversity were stored in a refrigerator at $4^{\circ} \mathrm{C}$.

\section{Nematode extraction and identification}

Soil nematodes were extracted from $100 \mathrm{~g}$ of wet soil for $48 \mathrm{~h}$ using the modified Baermann tray method (Barker 1985). Total nematodes in each sample were counted under an anatomical lens. One-quarter of the soil nematodes in each sample were identified to the genus level with an Olympus microscope (400x and 1000x). All soil nematodes were assigned to trophic groups (plant parasites, Pp; bacterivores, Ba; 
fungivores, F; and omnivores/predators, Op) (Yeates et al. 1993) and life history (Bongers and Bongers 1998). The abundances of total nematodes and each taxonomic group were converted to the individuals per $100 \mathrm{~g}$ of dry soil. The nematode length $(\mu \mathrm{m})$ and maximum body diameter were measured for metabolic function calculation with an ocular micrometre.

\section{Calculation of community structure indices}

For soil nematodes, the Shannon-Weaver index $\left(\mathrm{H}^{\prime}\right)$ and maturity indices of plant-parasitic nematodes (PPI) and free-living nematodes (MI) were calculated to represent the soil nematode diversity and lifehistory characteristics (Shannon and Weaver 1949; Bongers 1990). The enrichment index (EI) and structure index (SI) were calculated to estimate the effect of grazing on the soil food web condition (Ferris et al. 2001). We also calculated the soil nematode metabolic footprint, including the footprints of plant parasites (Ppf), bacterivores (Baf), fungivores (Fuf), and omnivores/predators (Opf), the enrichment footprint (ef) and the structure footprint (sf), based on nematode biomass (W) to estimate the contributions of soil nematodes to various ecosystem functions (Ferris 2010). The biomass carbon of soil nematodes was calculated as $52 \% \times 20 \% \mathrm{~W} / 100(\mu \mathrm{g})$ (Ferris 2010). The biomass carbon amounts of plant parasites, bacterivores, fungivores, omnivores/predators, and total soil nematodes are presented as PPc, Bac, Fuc, Opc, and Toc, respectively. The functional metabolic footprint is presented by the area of joining points on the SI vs. El plot according to (Ferris 2010): (SI-0.5 sf/k, El); (SI + 0.5 sf/k, El); (SI, El-0.5 ef $/ \mathrm{k}) ;(\mathrm{SI}, \mathrm{El}+0.5 \mathrm{ef} / \mathrm{k})$. The adjusted $\mathrm{k}$ value is 4 . For the plant community, the aboveground biomass (AGB), belowground biomass (BGB), Margarlef and Shannon diversity indices were calculated.

\section{Soil properties}

Details of soil physical and chemical property measurements were provided by Yan et al. (2016) and are briefly described here. Soil moisture was measured by drying soil for $72 \mathrm{~h}$ at $105^{\circ} \mathrm{C}$; the dichromate oxidation method was used to determine soil organic carbon (TOC); the molybdenum antimony resistance colorimetric method was used to determine total soil phosphorus (TP); the alkali diffusion method was applied to determine the soil available nitrogen (SAN); sodium bicarbonate extraction was used to determine the soil available phosphorus (SAP); the electrode method was used to measure soil $\mathrm{pH}$; and the ring knife method was used to measure soil bulk density (SBD).

\section{Data analysis}

The effects of grazing intensity on the abundance, biomass, ecological index, and metabolic footprint of soil nematodes were tested by Tukey's test of multiple comparisons with one-way ANOVA $(P<0.05)$. Nonmetric multidimensional scaling (NMDS) based on Bray curtis distance was applied to analyse composition changes at levels of genus. Principal component analysis (PCA) was conducted to assess the relationships between the community structure of soil nematodes and environmental factors. In the PCA, soil nematode composition at the genus level was the response variable, and biotic (AGB and BGB) and abiotic factors (soil physical and chemical properties) were explanatory variables. A structural equation model (SEM) was performed to explore the direct effect of grazing on soil nematode diversity 
and the indirect effects via changes in AGB, BGB, and soil physical and chemical properties. In the SEM analysis, the maximum likelihood estimation method was used to parameterize the model in Amos version 17.0.2 (SPSS Inc.). The chi-square test, its associated $p$ value, and the comparative fit index (CFI) were used to assess the model. PCA was performed in CANOCO version 5.0 software, and all other statistical tests were conducted using the SPSS version 16.0 software package (SPSS, Chicago, IL, USA).

\section{Results}

\section{Effect of grazing intensity on abundance of soil nematodes}

In total, 53 and 39 taxa were observed in the $0-10 \mathrm{~cm}$ and $10-20 \mathrm{~cm}$ soil layers, respectively (Table S1). Grazing affected the abundance of soil nematodes (Table 1). In the $0-10 \mathrm{~cm}$ soil layer, both $\mathrm{G} 2$ and G3 decreased the abundance of plant parasites compared to G0. The abundance of bacterivores and omnivores/predators was not affected by grazing compared to G0, but G3 decreased the abundance of bacterivores, and both $\mathrm{G} 3$ and $\mathrm{G} 2$ decreased the abundance of omnivores/predators compared to $\mathrm{G} 1$. Both G2 and G3 showed trends of decreased abundance of fungivores, but no difference was observed compared to G0. G3 (1702 individuals per $100 \mathrm{~g}$ of dry soil) significantly decreased the total abundance of soil nematodes compared to G0 (2821 individuals per $100 \mathrm{~g}$ of dry soil) and G1 (3344 individuals per $100 \mathrm{~g}$ of dry soil). $\mathrm{G} 1$ showed a tendency to increase nematode abundance, but the difference was not significant compared to G0. In the 10-20 cm soil layer, G3 decreased the abundances of plant parasites, fungivores, omnivores/predators and total soil nematodes compared to G0 (Table 1). G2 decreased the abundance of fungivores compared to $\mathrm{G} 0$ and $\mathrm{G} 1$. Both $\mathrm{G} 1$ and $\mathrm{G} 2$ also decreased the abundance of omnivores/predators compared to G0. G3 decreased the abundance of bacterivores compared to G1. There was no difference in the abundance of plant parasites, bacterivores, or total soil nematodes among G0, G1 and G2. 
Table 1

Soil nematode abundances (individuals per $100 \mathrm{~g}$ of dry soil) in the $0-10 \mathrm{~cm}$ and $10-20 \mathrm{~cm}$ soil layers across a grazing intensity gradient. Values are means \pm standard errors

\begin{tabular}{|c|c|c|c|c|c|}
\hline Grazing intensity & PP & $\mathrm{Ba}$ & $\mathrm{Fu}$ & Op & To \\
\hline \multicolumn{6}{|l|}{$0-10 \mathrm{~cm}$} \\
\hline G0 & $948 \pm 102 a$ & $786 \pm 119 a b$ & $689 \pm 174$ & $398 \pm 106 a b$ & $2821 \pm 500 a b$ \\
\hline G1 & $1088 \pm 62 a$ & $1023 \pm 128 a$ & $685 \pm 98$ & $548 \pm 110 a$ & $3344 \pm 376 a$ \\
\hline G2 & $554 \pm 101 b$ & $851 \pm 133 a b$ & $465 \pm 89$ & $334 \pm 21 b$ & $2204 \pm 306 b c$ \\
\hline G3 & $443 \pm 74 b$ & $614 \pm 115 b$ & $443 \pm 96$ & $202 \pm 31 b$ & $1702 \pm 290 c$ \\
\hline \multicolumn{6}{|l|}{$10-20 \mathrm{~cm}$} \\
\hline G0 & $682 \pm 72 a$ & $401 \pm 41 a b$ & $352 \pm 52 a$ & $200 \pm 26 a$ & $1635 \pm 169 a$ \\
\hline G1 & $431 \pm 138 \mathrm{ab}$ & $548 \pm 75 a$ & $351 \pm 51 a$ & $67 \pm 20 b$ & $1397 \pm 271 a b$ \\
\hline G2 & $441 \pm 97 \mathrm{ab}$ & $447 \pm 153 a b$ & $191 \pm 69 b$ & $52 \pm 15 b$ & $1129 \pm 327 a b$ \\
\hline G3 & $247 \pm 65 b$ & $277 \pm 58 b$ & $185 \pm 32 b$ & $65 \pm 10 b$ & $774 \pm 146 b$ \\
\hline \multicolumn{6}{|c|}{$\begin{array}{l}\mathrm{PP}, \mathrm{Ba}, \mathrm{Fu}, \mathrm{Op} \text {, and To represent plant parasites, bacterivores, fungivores, omnivore/predators, and } \\
\text { total soil nematodes, respectively. Grazing intensities G0, G1, G2 and G3 indicate } 0.00,0.23,0.46 \text { and } \\
0.92 \mathrm{AU} \mathrm{ha}^{-1} \text {, respectively. Means with the same column, same depth and followed by the same lowe } \\
\text { case letter are not significantly different }(p>0.05) \text {. }\end{array}$} \\
\hline
\end{tabular}

\section{Effect of grazing intensity on community diversity of soil nematodes}

Grazing affected the community composition of soil nematodes (Fig. 1). NMDS analysis showed that G3 was clearly separated from G0, G1 and G2 in both $0-10 \mathrm{~cm}$ and $10-20 \mathrm{~cm}$ soil layers. In $0-10 \mathrm{~cm}$ soil layers, soil nematode community structure developed along the direction from $\mathrm{G} 1$ to $\mathrm{G} 0, \mathrm{G} 2$ and $\mathrm{G} 3$, while in $10-20 \mathrm{~cm}$ soil layer, there was no clear development direction of soil nematode community structure among G0, G1 and G2. The ecological indices of soil nematodes changed over a gradient of grazing intensity (Table 2). In the $0-10 \mathrm{~cm}$ soil layer, both $\mathrm{G} 2$ and $\mathrm{G} 3$ decreased the $\mathrm{H}^{\prime}$ value, and the $\mathrm{H}^{\prime}$ value showed a decreasing trend with an increase in grazing intensity. G2 decreased the PPI value compared to G0, but no difference was observed between G3 and G0. The Ml value was lowest in G3, and it also showed a decreasing trend with an increase in grazing intensity. In the 10-20 cm soil layer, all grazing treatments decreased the values of $\mathrm{H}^{\prime}$ and MI compared to G0. G3 increased the PPI value, while there was no difference in PPI values among G0, G1, and G2 (Table 2). 
Table 2

Nematode ecological indices in the $0-10 \mathrm{~cm}$ and $10-20 \mathrm{~cm}$ soil layers across a grazing intensity gradient. Values are means \pm standard errors

\begin{tabular}{|lllllllll|}
\hline $\begin{array}{l}\text { Ecological } \\
\text { index }\end{array}$ & $\mathbf{0 - 1 0} \mathbf{~ c m}$ & \multicolumn{7}{c|}{$\mathbf{1 0 - 2 0 \mathbf { c m }}$} \\
\cline { 2 - 10 } & $\mathbf{G 0}$ & $\mathbf{G 1}$ & $\mathbf{G 2}$ & $\mathbf{G 3}$ & $\mathbf{G 0}$ & $\mathbf{G 1}$ & $\mathbf{G 2}$ & $\mathbf{G 3}$ \\
\hline $\mathrm{H}$ & $3.29 \pm$ & $3.31 \pm$ & $3.12 \pm$ & $2.95 \pm$ & $3.06 \pm$ & $2.69 \pm$ & $2.57 \pm$ & $2.74 \pm$ \\
& $0.06 \mathrm{a}$ & $0.12 \mathrm{a}$ & $0.02 \mathrm{~b}$ & $0.04 \mathrm{c}$ & $0.04 \mathrm{a}$ & $0.07 \mathrm{~b}$ & $0.03 \mathrm{c}$ & $0.11 \mathrm{~b}$ \\
\hline $\mathrm{PPI}$ & $2.57 \pm$ & $2.44 \pm$ & $2.32 \pm$ & $2.71 \pm$ & $2.38 \pm$ & $2.47 \pm$ & $2.41 \pm$ & $2.79 \pm$ \\
& $0.07 \mathrm{ab}$ & $0.02 \mathrm{bc}$ & $0.07 \mathrm{c}$ & $0.08 \mathrm{a}$ & $0.03 \mathrm{~b}$ & $0.03 \mathrm{~b}$ & $0.11 \mathrm{~b}$ & $0.04 \mathrm{a}$ \\
$\mathrm{MI}$ & $2.59 \pm$ & $2.70 \pm$ & $2.49 \pm$ & $2.41 \pm$ & $2.53 \pm$ & $2.15 \pm$ & $2.18 \pm$ & $2.26 \pm$ \\
& $0.04 \mathrm{ab}$ & $0.04 \mathrm{a}$ & $0.10 \mathrm{bc}$ & $0.06 \mathrm{c}$ & $0.02 \mathrm{a}$ & $0.04 \mathrm{c}$ & $0.09 \mathrm{bc}$ & $0.05 \mathrm{~b}$ \\
\hline
\end{tabular}

\section{Effect of grazing intensity on the biomass carbon of soil nematodes}

In the $0-10 \mathrm{~cm}$ soil layer, G3 decreased the biomass carbon of plant parasites, fungivores, and total soil nematodes compared to G0 (Table 3). G2 decreased the biomass carbon of plant parasites and fungivores compared to G0. Compared with G0, G1 increased the biomass carbon of omnivores/predators but had no effect on the biomass carbon of other nematode trophic groups or total soil nematodes. The biomass carbon amounts of plant parasites, omnivores/predators and total soil nematodes were higher in $\mathrm{G} 1$ than in $\mathrm{G} 3$. In the $10-20 \mathrm{~cm}$ soil layer, $\mathrm{G} 3$ decreased the biomass carbon amounts of bacterivores, fungivores, omnivores/predators and total soil nematodes compared to G0 (Table 3), and $\mathrm{G} 2$ decreased the biomass carbon amounts of fungivores and omnivores/predators. There was no difference in the biomass carbon of soil nematodes between G1 and G0 except G1, which decreased the biomass carbon of omnivores/predators. No difference was observed in the biomass carbon of soil nematodes among G1, G2, and G3 in the 10-20 cm soil layer. 
Table 3

Biomass carbon of soil nematodes ( $\mu \mathrm{g} 100 \mathrm{~g}^{-1}$ dry soil) in the $0-10 \mathrm{~cm}$ and $10-20 \mathrm{~cm}$ soil layers across a grazing intensity gradient. Values are means \pm standard errors

\begin{tabular}{|c|c|c|c|c|c|}
\hline Grazing intensity & PPc & Bac & Fuc & Opc & Toc \\
\hline \multicolumn{6}{|l|}{$0-10 \mathrm{~cm}$} \\
\hline G0 & $5.2 \pm 0.8 a$ & $11.5 \pm 0.4$ & $3.5 \pm 0.9 a$ & $2.8 \pm 0.8 b$ & $\begin{array}{l}23.0 \pm \\
2.8 a\end{array}$ \\
\hline G1 & $4.9 \pm 0.3 a$ & $13.1 \pm 2.2$ & $3.0 \pm 0.3 a b$ & $4.6 \pm 0.9 a$ & $\begin{array}{l}25.6 \pm \\
3.7 a\end{array}$ \\
\hline G2 & $2.3 \pm 0.4 b$ & $10.9 \pm 2.0$ & $1.9 \pm 0.4 c$ & $2.8 \pm 0.3 b$ & $\begin{array}{l}18.0 \pm \\
2.4 a b\end{array}$ \\
\hline G3 & $2.4 \pm 0.5 b$ & $8.8 \pm 1.8$ & $2.1 \pm 0.4 b c$ & $1.8 \pm 0.2 b$ & $\begin{array}{l}15.1 \pm \\
2.7 b\end{array}$ \\
\hline \multicolumn{6}{|l|}{$10-20 \mathrm{~cm}$} \\
\hline G0 & $2.9 \pm 0.3$ & $7.8 \pm 0.8 a$ & $1.8 \pm 0.3 a$ & $2.0 \pm 0.2 \mathrm{a}$ & $\begin{array}{l}14.5 \pm \\
1.3 a\end{array}$ \\
\hline G1 & $2.1 \pm 0.7$ & $6.7 \pm 1.1 \mathrm{ab}$ & $1.4 \pm 0.2 \mathrm{ab}$ & $0.8 \pm 0.2 b$ & $\begin{array}{l}11.0 \pm \\
2.1 \mathrm{ab}\end{array}$ \\
\hline G2 & $1.7 \pm 0.4$ & $6.5 \pm 2.1 \mathrm{ab}$ & $1.0 \pm 0.4 b$ & $0.5 \pm 0.2 b$ & $\begin{array}{l}9.8 \pm \\
2.8 a b\end{array}$ \\
\hline G3 & $1.7 \pm 0.5$ & $4.0 \pm 0.9 b$ & $0.9 \pm 0.2 b$ & $0.8 \pm 0.1 b$ & $\begin{array}{l}7.4 \pm \\
1.4 \mathrm{~b}\end{array}$ \\
\hline \multicolumn{6}{|c|}{$\begin{array}{l}\text { PPc, Bac, Fuc, Opc, and Toc represent the biomass carbon of plant parasites, bacterivores, fungivores, } \\
\text { omnivores/predators, and total soil nematodes, respectively. Grazing intensities } \mathrm{G} 0, \mathrm{G} 1, \mathrm{G} 2 \text { and } \mathrm{G} 3 \\
\text { indicate } 0.00,0.23,0.46 \text { and } 0.92 \mathrm{AU} \mathrm{ha}^{-1} \text {, respectively. Means in the same column, the same depth } \\
\text { and followed by the same lower case letter are not significantly different }(p>0.05)\end{array}$} \\
\hline
\end{tabular}

Effect of grazing intensity on the metabolic footprints of soil nematodes

In the $0-10 \mathrm{~cm}$ soil layer, G3 decreased the metabolic footprints of plant parasites, fungivores and total soil nematodes compared to G0 (Table 4). G2 decreased the metabolic footprints of plant parasites and fungivores compared to G0. There was a trend of larger metabolic footprints of soil nematodes in G1 compared to G0, but the differences were not significant for any of the trophic groups. The metabolic footprints of plant parasites, omnivores/predators and total soil nematodes were higher in G1 than in G3. In the 10-20 cm soil layer, G3 decreased the metabolic footprints of bacterivores, fungivores, omnivores/predators and total soil nematodes relative to G0 (Table 4), and G2 decreased the metabolic footprints of fungivores, omnivores/predators and total soil nematodes relative to G0. There was no difference in the metabolic footprints of soil nematodes among G1, G2, and G3. 
Table 4

Metabolic footprints of soil nematodes $\left(\mu \mathrm{g} 100 \mathrm{~g}^{-1}\right.$ dry soil) in the $0-10 \mathrm{~cm}$ and $10-20 \mathrm{~cm}$ soil layers across a grazing intensity gradient. Values are means \pm standard errors

\begin{tabular}{|c|c|c|c|c|c|}
\hline Grazing intensity & PPf & Baf & Fuf & Opf & Tof \\
\hline \multicolumn{6}{|l|}{$0-10 \mathrm{~cm}$} \\
\hline G0 & $67.7 \pm 11.0 \mathrm{a}$ & $92.9 \pm 5.2$ & $37.9 \pm 9.9 a$ & $\begin{array}{l}47.7 \pm \\
13.0 \mathrm{ab}\end{array}$ & $\begin{array}{l}246.2 \pm \\
38.6 a b\end{array}$ \\
\hline G1 & $61.1 \pm 4.9 a$ & $108.3 \pm 17.7$ & $35.3 \pm 4.3 a b$ & $\begin{array}{l}74.2 \pm \\
15.5 a\end{array}$ & $\begin{array}{l}278.9 \pm \\
40.8 \mathrm{a}\end{array}$ \\
\hline G2 & $28.3 \pm 5.0 b$ & $88.5 \pm 15.7$ & $20.9 \pm 4.0 b$ & $\begin{array}{l}46.8 \pm \\
5.3 a b\end{array}$ & $\begin{array}{l}184.5 \pm \\
20.2 \mathrm{bc}\end{array}$ \\
\hline G3 & $32.1 \pm 6.0 b$ & $71.6 \pm 14.5$ & $22.8 \pm 4.6 b$ & $\begin{array}{l}27.8 \pm \\
4.0 \mathrm{~b}\end{array}$ & $\begin{array}{l}154.3 \pm \\
26.1 \mathrm{c}\end{array}$ \\
\hline \multicolumn{6}{|l|}{$10-20 \mathrm{~cm}$} \\
\hline G0 & $36.9 \pm 3.8$ & $59.6 \pm 6.3 a$ & $19.1 \pm 2.6 a$ & $\begin{array}{l}30.8 \pm \\
3.4 a\end{array}$ & $\begin{array}{l}146.3 \pm \\
13.4 a\end{array}$ \\
\hline G1 & $25.9 \pm 8.2$ & $55.9 \pm 8.8 a b$ & $15.6 \pm 2.5 a b$ & $\begin{array}{l}11.2 \pm \\
2.6 b\end{array}$ & $\begin{array}{l}108.7 \pm \\
20.9 a b\end{array}$ \\
\hline G2 & $22.1 \pm 5.4$ & $52.3 \pm 16.9 a b$ & $10.6 \pm 3.7 b$ & $\begin{array}{l}8.1 \pm \\
2.8 \mathrm{~b}\end{array}$ & $\begin{array}{l}93.2 \pm \\
25.7 b\end{array}$ \\
\hline G3 & $21.4 \pm 5.9$ & $31.0 \pm 6.9 b$ & $10.0 \pm 1.9 b$ & $\begin{array}{l}11.6 \pm \\
1.6 \mathrm{~b}\end{array}$ & $\begin{array}{l}74.1 \pm \\
13.4 \mathrm{~b}\end{array}$ \\
\hline \multicolumn{6}{|c|}{$\begin{array}{l}\text { PPf, Baf, Fuf, Opf, Tof represent metabolic footprints of plant parasites, bacterivores, fungivores, } \\
\text { omnivores/predators, and total soil nematodes, respectively. Grazing intensities } \mathrm{G} 0, \mathrm{G} 1, \mathrm{G} 2 \text { and } \mathrm{G} 3 \\
\text { indicate } 0.00,0.23,0.46 \text { and } 0.92 \mathrm{AU}^{-1} \text {, respectively. Means in the same column, the same depth } \\
\text { and followed by the same lower case letter are not significantly different }(p>0.05)\end{array}$} \\
\hline
\end{tabular}

The total area of footprints on structure and enrichment coordinates indicates the functional metabolic footprints of soil nematodes. In the $0-10 \mathrm{~cm}$ soil layer, the metabolic footprints of soil nematodes were greater in $\mathrm{G} 1$ than in $\mathrm{G0}$, and $\mathrm{G} 3$ clearly decreased the functional metabolic footprints of soil nematodes (Fig. 2). G0, G1, and G2 were located in the lower right quadrant in the $0-10 \mathrm{~cm}$ soil layer, and $\mathrm{G} 3$ was partly in the lower left degraded quadrant. In the $10-20 \mathrm{~cm}$ soil layer, the metabolic functional footprints of all grazing intensities were correspondingly smaller than those of the $0-10 \mathrm{~cm}$ soil layer, and all grazing treatments decreased the functional metabolic footprints of soil nematodes compared to $\mathrm{G} 0$. In the 10-20 cm soil layer, all grazing treatments moved to the lower left degraded quadrant, but G0 was still located in the lower right quadrant.

\section{The relationship between soil environmental factors and the community structure of soil nematodes}

Grazing affected the composition of soil nematode genera based on principal component analysis (PCA) (Fig. $3 a$ and b). The first two components of PCA explained $55.1 \%$ and $21.5 \%$ of the variance in nematode 
genus data in the $0-10 \mathrm{~cm}$ layer and $50.5 \%$ and $24.6 \%$ of the variance in nematode genus data in the 10-20 cm layer, respectively. At 0-10 cm depth, G2 and G3 were clearly separated from G0 and G1 on PCA axis 1 (Fig. 3a). G3 was characterized by Aphelenchus, Acrobeles and Criconemella. G2 was characterized by Monhystera and Wilsonema. The first axis was mainly driven by AGB, BGB, soil moisture, Shannon diversity of grass and SBD, and the main driving factors of axis 2 were soil moisture, BGB and Margarlef of grass. At 10-20 cm, G3 was clearly separated from G0, G1, and G2, and G1 and G2 were also separated from G0 on axis 2 (Fig. 3b). G3 was characterized by Acrobeles, Protorhabditis, Tylenchorhynchus, Eudorylaimus and Tylencholaimellus. G2 was characterized by Trischistoma and Criconemella. G1 was characterized by Aphelenchus, Cervidellus, Heterodera, and Lelenchus. PCA axis 1 was mainly driven by AGB, pH and soil moisture, and PCA axis 2 was mainly driven by soil moisture, BGB, SBD and Shannon diversity of grass.

The SEM model showed that grazing significantly and negatively affected grass AGB and soil moisture in the $0-10 \mathrm{~cm}$ soil layer $(p<0.05)$ (Fig. 4a). Grass AGB had significant effects on soil moisture and Shannon diversity of soil nematodes. Grazing and soil moisture positively affected the Shannon diversity of soil nematodes. In the $10-20 \mathrm{~cm}$ soil layer, grazing significantly and negatively affected the grass AGB, BGB and the Shannon diversity of soil nematodes (Fig. 4b). However, neither AGB nor BGB had significant effect on the Shannon diversity of soil nematodes either directly or indirectly.

\section{Discussion}

\section{Effect of grazing on abundance of soil nematodes}

Grazing affected the abundance of soil nematodes, and the effect of grazing intensity on soil nematode abundance was weakened in the $10-20 \mathrm{~cm}$ soil layer compared to the $0-10 \mathrm{~cm}$ soil layer (Table 1 ). This is likely because the effect of grazing on the soil environment is greater at $0-10 \mathrm{~cm}$ near the surface soil layer. Another reason may be that soil nematodes in the $0-10 \mathrm{~cm}$ soil layer are normally more abundant than those in the $10-20 \mathrm{~cm}$ soil layer, so the changes in the abundance of soil nematodes in the $0-10$ $\mathrm{cm}$ layer caused by external factors were more obvious. Previous studies has found that biological soil crusts had a stronger impact on soil nematodes in the topsoil layers than in deeper soil layers (Liu et al. 2013; Guan et al. 2018). Our results demonstrated that the effect of grazing on the soil nematode community was lower in the deeper soil layer.

\section{Effect of grazing on community diversity of soil nematodes}

Ecological indices of soil nematodes consolidate the characteristics, activities and functions of a large number of soil nematodes into a single metric and can provide a deeper understanding of the grazing effect on the soil nematode community and ecological function (Yeates 2003). In the 0-10 cm soil layer, both $\mathrm{G} 2$ and $\mathrm{G} 3$ decreased the $\mathrm{H}^{\prime}$ value of soil nematodes, and the $\mathrm{H}^{\prime}$ value showed a decreasing trend with an increase in grazing intensity from $\mathrm{G} 1$ to G3. This indicates that serious disturbance by intensive grazing decreases the diversity of soil nematodes. This is inconsistent with previous findings that no significant difference was observed in the Shannon diversity of soil nematodes among different grazing 
intensities (Hu et al. 2015). The different grassland environments, grazing intensities, and grazing animals could explain the different findings. We conducted our study in Hulun Buir meadow steppe with four grazing intensities of $0,0.230 .46$ and 0.92 mature cattle ha $^{-1}$, and $\mathrm{Hu}$ et al. (2015) conducted their study in Tibetan Plateau meadows with three grazing intensities, 1, 1.1, and 1.5 yaks ha $^{-1}$; all of their grazing intensities were higher than any of the grazing intensities of our study.

The MI value decreased with an increase in grazing intensity, suggesting that grazing disturbs soil ecosystems based on communities of free-living soil nematodes. Our results are inconsistent with previous findings that higher Ml occurred in grazed plots (Wang et al. 2006). The different results are likely due to the voided faeces effect of herbivores on soil nematodes. Wang et al. (2006) collected soil samples at least $1 \mathrm{~m}$ away from any visible voided faeces deposition, while in our random sampling, we avoided sampling within a faeces deposit but allowed sampling within a one-metre radius. The input of animal faeces can increase the abundance of bacterivores and fungivores with low c-p values (Mills et al. 2011), which leads to a low MI value.

\section{Effect of grazing intensity on carbon utilization of soil nematodes}

In both the $0-10 \mathrm{~cm}$ and $10-20 \mathrm{~cm}$ soil layers, G3 and $\mathrm{G} 2$ showed trends of decreasing biomass carbon of soil nematodes compared to G0 (Table 3). This is likely due to intensive grazing reducing the BGB of grass and the corresponding organic matter input. Plant roots provide an important carbon source for soil microbes in grassland ecosystems (Coleman et al. 1983). However, intensive grazing reduced root biomass and consequently decreased the carbon aggregation surrounding the root. Although approximately half of the carbon in the AGB of grass is returned to the soil as faeces, grass is limited or scarce to cattle in heavily grazed plots, thus reducing the carbon returned to the soil. The reduction in the carbon source used by microorganisms will naturally affect the biomass carbon located at high-level positions in the soil food web. This may explain the lower biomass carbon of soil nematodes in G2 and G3. There was a gradient effect of grazing on the biomass carbon of soil nematodes in the $0-10 \mathrm{~cm}$ soil layer, but the effect was weakened in the $10-20 \mathrm{~cm}$ soil layer, suggesting that the grazing influence on the activity of soil nematodes is mainly confined to the uppermost soil layer. This is likely because organic matter input via faeces and soil disturbance by grazing animal foot traffic have stronger influences on the topsoil layer than on the deeper soil layer. Additionally, grass roots are concentrated in the near surface layer, and the reduction in grass BGB with intensive grazing has a greater effect on organic matter input in the $0-10 \mathrm{~cm}$ layer.

The metabolic footprints of soil nematodes represent the carbon entering the soil food web via nematode channels (Ferris 2010). In both the $0-10 \mathrm{~cm}$ and $10-20 \mathrm{~cm}$ soil layers, G3 and G2 showed trends of decreasing the metabolic footprints of soil nematodes (Table 4). This is in line with the above results that intensive grazing reduced the abundance and biomass carbon of nematodes (Tables 1 and 3 ). The metabolic footprints are the combination of carbon used for reproduction and respiration of soil nematodes. Yan et al. (2017) found that $\mathrm{CO}_{2}$ flux significantly decreased with increasing grazing intensity. Our results are in agreement and indicate that intensive grazing reduces the metabolic activity 
of soil nematodes. The changing trend of the soil nematode metabolic footprint is the same as that of the $\mathrm{CO}_{2}$ flux under different grazing intensities. A previous study has showed that nematode activity contributes to $\mathrm{CO}_{2}$ flux (Ferris et al. 1995).

The functional metabolic footprints of soil nematodes are the total area of the footprints plotted on enrichment and structure coordinates. In the $0-10 \mathrm{~cm}$ soil layer, G3 clearly decreased the functional metabolic footprints of soil nematodes, while there was a small increase from G0 to G1 (Fig. 2). Wang et al. (2018) reported an increasing trend of structure and enrichment footprints in grazed meadows with shrub vegetation. This may be attributed to light grazing increasing root exudation, which then promotes the activity of soil biota. However, intensive grazing can seriously decrease root biomass and soil ecological processes. In G3, we even observed patches of bare soil without grass cover. Previous studies have found that clipping wheatgrass can increase root exudation (Bokhari and Singh 1974), and defoliation of white clover and Italian ryegrass can increase root efflux of nitrate and ammonium nitrogen (McDuff and Jackson 1992). Our results suggest that light grazing can promote the contribution of soil nematodes to soil carbon cycling, but intensive grazing decreases the function of soil nematodes in the soil food web in the $0-10 \mathrm{~cm}$ soil layer. In the $10-20 \mathrm{~cm}$ soil layer, the functional metabolic footprints of soil nematodes of all grazing intensities were correspondingly lower than those of the $0-10 \mathrm{~cm}$ soil layer (Fig. 2), suggesting that the contribution of soil nematodes to carbon cycling is larger in topsoil than in the deeper soil layer and that grazing will not alter the function of soil nematodes in the deeper soil layer.

\section{Potential driving factors and paths of grazing on soil nematode community structure}

Intensive grazing changed the composition of soil nematode genera based on NMDS and PCA analysis (Figs. 1 and 3). In the $0-10 \mathrm{~cm}$ soil layer, G3 was characterized by the fungivore Aphelenchus and the plant parasite Criconemella. This is consistent with previous studies showing that grazing can increase the abundance of fungivores in shortgrass steppe and the Tibetan Plateau (Wall-Freckman et al. 1998; Hu et al. 2015). In contrast, G2 was characterized by the bacterivores Monhystera and Wilsonema. Previous studies also showed that grazing stimulated bacterivores (Sørensen et al. 2009; Wang et al. 2018). This is likely due to manure amendment from animals under moderate grazing increasing the growth and activity of bacteria (Xun et al. 2018), as manure is bacterivorous food. In the $10-20 \mathrm{~cm}$ soil layer, G3 was characterized by different nematode genera from those in the $0-10 \mathrm{~cm}$ soil layer, and the main driving factors of PCA axis 1 were AGB, soil pH, and soil moisture, which were also different from those in the 0$10 \mathrm{~cm}$ soil layer (Fig. 3b). Both AGB and soil moisture were also among the main driving factors of the community structure of soil nematodes in the $0-10 \mathrm{~cm}$ layer, suggesting that these two environmental factors are stable drivers of soil nematode composition under grazing in both soil layers. The close relationship between soil pH and soil nematodes has been proven by previous studies (Fiscus and Neher 2002; Li et al. 2010; Pan et al. 2016). Our results suggest that grazing changes the community composition of soil nematodes, and the selective pressures of grazing as the driving factors on soil nematode community structure are different in different soil layers. 
Our study found that grazing affected soil nematode diversity by different paths in the $0-10 \mathrm{~cm}$ and $10-$ $20 \mathrm{~cm}$ soil layers (Fig. 4a and b). In the $0-10 \mathrm{~cm}$ soil layer, grazing had significant direct effect on the Shannon diversity of soil nematodes, and it also indirectly affected the Shannon diversity of soil nematodes by modifying grass AGB and soil moisture. Our results were in line with previous findings that soil moisture can influence soil nematode community structure (Landesman et al. 2011). SEM analysis showed that grazing had positive effect on soil nematode diversity in $0-10 \mathrm{~cm}$ soil layer, which is not inconsistent with the low soil nematode diversity of intensive grazing above, because grazing also regulates the Shannon diversity of soil nematodes via negative effects on soil moisture and grass AGB. However, soil moisture and grass AGB had a positive effect on soil nematode diversity. Our result was supported by previous study that hither species richness of soil nematodes was found on seriously grazing site (Hu et al. 2015). This is probably because grazing increased the diversity of available food resources of soil nematodes, such as animal waste can increase the abundance of soil microorganisms upon which bacterivores and fungivores feed. In the 10-20 cm soil layer, grazing negatively and directly affected soil nematode diversity (Fig. 3b). This may be due to differences in the root distribution and distribution of cattle faeces in different soil layers. Several studies have shown that root exudation is significantly affected by aboveground defoliation and herbivory (McDuff and Jackson 1992; Shand et al. 1994). Root exudation affects the community structure of soil microorganisms, which provide food resources for soil microfauna. Soil microorganisms are the food of bacterivores, fungivores and omnivores, so a shift in their abundance and diversity will also influence diversity of soil nematodes. Grass roots are mainly distributed in topsoil, and cattle faeces are deposited on the soil surface and are mixed with topsoil by rain, animal foot traffic, and earthworms; therefore, grazing could modify soil nematode diversity via grass AGB and soil physical and chemical properties in the $0-10 \mathrm{~cm}$ soil layer. However, there are fewer grass roots and less mixing of cattle faeces in the $10-20 \mathrm{~cm}$ soil layer, so grazing has a more prominent effect on soil nematodes than other factors. Our results suggest that grazing affects the soil nematode community, but the paths by which the effects occur are different in different soil layers. In grasslands, grazing may affect the structure and function of soil nematodes in underground ecosystems via other biotic or abiotic factors, such as vegetation type and soil type, which needs further research.

\section{Conclusions}

Our results showed that grazing affects the community structure and activity of soil nematodes in both the $0-10 \mathrm{~cm}$ and $10-20 \mathrm{~cm}$ soil layers. However, the effect of grazing gradients was weaker in the 10-20 $\mathrm{cm}$ soil layer than in the $0-10 \mathrm{~cm}$ soil layer. Light grazing showed trends of increasing the abundance, biomass carbon and metabolic footprints of soil nematodes at $0-10 \mathrm{~cm}$. Intensive grazing changed the composition of soil nematodes and degraded the food web structure of soil nematodes in both soil layers. Soil physical and chemical properties, AGB and BGB played important roles in the differentiation of soil nematode community composition. In the $0-10 \mathrm{~cm}$ soil layer, grazing directly and indirectly affected the soil nematode abundance via AGB and soil moisture; however, grazing directly affected the soil nematode abundance in the $10-20 \mathrm{~cm}$ soil layer. Our findings indicate that grazing affects soil 
nematode community structure and function via different paths in different soil layers. Our study also provides evidence for increasing the understanding of the linkage between aboveground and belowground ecosystems. The community structure of soil nematodes can well reflect the impact of grazing on the biodiversity of grassland ecosystems and can also reflect the sustainability of grazing grassland ecosystems.

\section{Abbreviations}

H' Shannon-Weaver index

PPI Maturity index of plant-parasitic nematodes

MI Maturity index of free-living nematodes

El Enrichment index

SI Structure index

AGB Aboveground biomass

BGB Belowground biomass

TOC Soil organic carbon

TP Total soil phosphorus

SAN Soil available nitrogen

SAP Soil available phosphorus

SBD Soil bulk density

NMDS Nonmetric multidimensional scaling

PCA Principal component analysis

SEM Structural equation model

\section{Declarations}

\section{Acknowledgments}

This work was supported by the National Natural Science Foundation of China $(41771205,41877342$, 32071636 and 31971769), the National Key Research and Development Programme of China (2017YFE0104500 and 2016YFC0500601), Special Funding for the Modern Agricultural Technology 
System from the Chinese Ministry of Agriculture (CARS-34), Fundamental Research Funds for Central Nonprofit Scientific Institutions (1610132018009), and the State Key Laboratory of Grassland AgroEcosystems (Lanzhou University) (SKLGAE-2019-07). We would like to thank the staff at the Hulun Buir Grassland Ecosystem Observation and Research Station for their contributions to field management and help with soil sampling.

\section{References}

1. Andriuzzi WS, Wall DH (2017) Responses of belowground communities to large aboveground herbivores: meta-analysis reveals biome-dependent patterns and critical research gaps. Global Change Biol 23:3857-3868. https://doi.org/10.1111/gcb.13675

2. Bardgett RD, Wardle DA, Yeates GW (1998) Linking above-ground and belowground interactions: how plant responses to foliar herbivory influence soil organisms. Soil Biol Biochem 30:1867-1878.

3. Barker KR. 1985. Nematode extraction and bioassays. In: Barker KR, Carter CC, Sasser JN (eds) An Advanced Treatise on Meloidogyne. North Carolina State University Graphics, Raleigh, pp 19-35.

4. Bokhari UG, Singh JS (1974) Effects of temperature and clipping on growth, carbohydrate reserves and root exudation of western wheatgrass in hydroponic culture. Crop Sci 14:790-794.

5. Bongers T (1990) The maturity index: an ecological measure of environmental disturbance based on nematode species composition. Oecologia 83:14-19.

6. Bongers T, Bongers M (1998) Functional diversity of nematodes. Appl Soil Ecol 10: 239-251.

7. Cao J, Yan R, Chen X, Wang X, Yu Q, Zhang Y, Ning C, Hou L, Zhang Y, Xin X (2019) Grazing affects the ecological stoichiometry of the plant-soil-microbe system on the Hulunber steppe, China. Sustainability 11:5226. https://doi.org/10.3390/su11195226

8. Chaieb M, Henchi B, Boukhris M (1996) Impact of clipping on root systems of three grasses species in Tunisia. J Range Manage 49:336-339.

9. Coleman DC, Reid CPP, Cole CV (1983) Biological strategies of nutrient cycles in soil systems. Adv Ecol Res 13:1-55.

10. Darby BJ, Neher DA, Housman DC, Belnap J (2011) Few apparent short-term effects of elevated soil temperature and increased frequency of summer precipitation on the abundance and taxonomic diversity of desert soil micro- and meso-fauna. Soil Biol Biochem 43:1474-1481. https://doi.org/10.1016/j.soilbio.2011.03.020

11. Ferris $\mathrm{H}$ (2010) Form and function: metabolic footprints of nematodes in the soil food web. Eur J Soil Biol 46: 97-104. https://doi.org/10.1016/j.ejsobi.2010.01.003

12. Ferris H, Bongers T, de Goade RGM (2001) A framework for soil food web diagnostics, extension of the nematode faunal analysis concept. Appl Soil Ecol 18:13-29. https://doi.org/10.1016/s09291393(01)00152-4

13. Ferris H, Lau S, Venette R (1995) Population energetics of bacterial-feeding nematodes: Respiration and metabolic rates based on $\mathrm{CO}_{2}$ production. Soil Biol Biochem 27:319-330. 
14. Fiscus DA, Neher DA (2002) Distinguishing sensitivity of free-living soil nematode genera to physical and chemical disturbances. Ecol Appl 12:565-575.

15. Freckman DW, Huang SP (1998) Response of the soil nematode community in a shortgrass steppe to long-term and short-term grazing. Appl Soil Ecol 9:39-44. https://doi.org/10.1016/S09291393(98)00051-1

16. Griffiths BS, Caul S, Thompson J, Birch ANE, Scrimgeour C, Andersen MN, Cortet J, Messéan A, Sausse C, Lacroix B, Krogh PH (2005) A comparison of soil microbial community structure, protozoa and nematodes in field plots of conventional and genetically modified maize expressing the Bacillus thuringiens is CrylAb Toxin. Plant Soil 275:135-146. https://doi.org/10.1007/s11104-005-1093-2

17. Guan P, Zhang X, Yu J, Cheng Y, Li Q, Andriuzzi WS, Liang W (2018) Soil microbial food web channels associated with biological soil crusts in desertification restoration: the carbon flow from microbes to nematodes. Soil Biol Biochem 116:82-90. https://doi.org/10.1016/j.soilbio.2017.10.003

18. Hokka V, Mikola J, Vertberg M, Setala H (2004) Interactive effects of defoliation and an AM fungus on plants and soil organisms in an experimental legume grass community. Oikos 106:73-84. https:// doi.org/10.2307/3548397

19. Hu J, Chen GR, Hassan WM, Chen H, Li J, Du G (2017) Fertilization influences the nematode community through changing the plant community in the Tibetan Plateau. Eur J Soil Biol 78:7-16. https://doi.org/10.1016/j.ejsobi.2016.11.001

20. Hu J, Wu J, Ma M, Nielsen U N, Wang J, Du G (2015) Nematode communities response to long-term grazing disturbance on Tibetan plateau. Eur J Soil Biol 69:24-32. https://doi.org/10.1016/j.ejsobi.2015.04.003

21. Ilmarinen K, Mikola J, Nieminen H, Vestberg M (2005) Does plant growth phase determine the response of plant and soil organisms to defoliation? Soil Biol Biochem 37:433-443. https://doi.org/10.1016/j.soilbio.2004.07.034

22. Ingham RE, Trofymow JA, Ingham ER, Coleman DC (1985) Interactions of bacteria, fungi, and their nematode grazers: effects on nutrient cycling and plant growth. Ecol Monogr 55:119-140.

23. Korthals GW, Smilauer P, Vandijk C, Van der Putten WH (2001) Linking above- and below-ground biodiversity: abundance and trophic complexity in soil as a response to experimental plant communities on abandoned arable land. Funct Ecol 15:506-514.

24. Landesman WJ, Treonis AM, Dighton J (2011) Effects of a one-year rainfall manipulation on soil nematode abundances and community composition. Pedobiologia 54:87-91. https://doi.org/10.1016/j.pedobi.2010.10.002

25. Li LH, Chen JQ, Zhang WH, Han XG (2020) Chinese Grassland Ecosystems, Springer, Berlin, pp 176220.

26. Li Q, Jiang Y, Liang W, Lou Y, Zhang E, Liang C (2010) Long-term effect of fertility management on the soil nematode community in vegetable production under greenhouse conditions. Appl Soil Ecol 46:111-118. https://doi.org/10.1016/j.apsoil.2010.06.016 
27. Liu Y, Li X, Xing Z, Zhao X, Pan Y (2013) Responses of soil microbial biomass and community composition to biological soil crusts in the revegetated areas of the Tengger Desert. Appl Soil Ecol 65:52-59. https://doi.org/10.1016/j.apsoil.2013.01.005

28. McDuff JH, Jackson SB (1992) Influx and efflux of nitrate and ammonium in Italian ryegrass and white clover roots. J Exp Bot 43:525-535. https://doi.org/10.1093/jxb/43.4.525

29. Mills AAS, Adl MS (2011) Changes in nematode abundances and body length in response to management intensive grazing in a low-input temperate pasture. Soil Biol Biochem 43:150-158. https://doi.org/10.1016/j.soilbio.2010.09.027

30. Pan F, Li N, Zou W, Han X, McLaughlin Neil B (2016) Soil nematode community structure and metabolic footprint in the early pedogenesis of a Mollisol. Eur J Soil Biol 77:17-25. https://doi.org/10.1016/j.ejsobi.2016.09.004

31. Rodrigues CVMA, Pedrosa EMR, Oliveira AKS, Leitão DAHS, Oliveira NJV (2010) Vertical distribution of nematode communities associated with sugarcane. Nematropica 41:05-11. https://doi.org/10.1002/jez.674

32. Shand CA, Macklon AES, Edwards AC, Smith S (1994) Inorganic and organic P in soil solutions from three upland soils. II. Effect of defoliation and fertilizer application. Plant Soil 160:161-170. https://doi.org/10.1007/BF00010142

33. Shannon CE, Weaver W (1949) The Mathematical theory of communication (pp. 117). University of Illinois, Urbana, pp 117.

34. Sørensen LI, Mikola J, Kyt€oviita MM, Olofsson J (2009) Trampling and spatial heterogeneity explain decomposer abundances in a sub-arctic grassland subjected to simulated reindeer grazing. Ecosystems 12: 830-842. https://doi.org/10.2307/40603637

35. Van der Putten W, Van der Stoel CD (1998) Plant parasitic nematodes and spatio- temporal variation in natural vegetation. Appl Soil Ecol 10:253-262. https://doi.org/10.1016/S0929-1393(98)00124-3

36. Wall-Freckman D, Huang SP (1998) Response of the soil nematode community in a shortgrass steppe to long-term and short-term grazing. Appl Soil Ecol 9:39-44. https://doi.org/10.1016/S09291393(98)00051-1

37. Wang KH, McSorley R, Bohlen P, Gathumbi SM (2006) Cattle grazing increases microbial biomass and alters soil nematode communities in subtropical pastures. Soil Biol Biochem 38:1956-1965. https:// doi.org/10.1016/j.soilbio.2005.12.019

38. Wang X, Nielsen UN, Yang X, Zhang L, Zhou X, Du G, Li G, Chen S, Xiao S (2018) Grazing induces direct and indirect shrub effects on soil nematode communities. Soil Biol Biochem 121:193-201. https://doi.org/10.1016/j.soilbio.2018.03.007

39. Wardle DA, Bardgett RD, Klironomos JN, Setälä H, van der Putten WH, Wall DH (2004) Ecological linkages between aboveground and belowground biota. Science 304:1629-1633. https:// doi.org/10.1126/science.1094875

40. Xun W, Yan R, Ren Y, Jin D, Xiong W, Zhang G, Cui Z, Xin X, Zhang R (2018) Grazing-induced microbiome alterations drive soil organic carbon turnover and productivity in meadow steppe. 
Microbiome 6:170. https://doi.org/10.1186/s40168-018-0544-y

41. Yan R, Tang H, Xin X, Chen B, Murray PJ, Yan Y, Wang X, Yang G (2016) Grazing intensity and driving factors affect soil nitrous oxide fluxes during the growing seasons in the Hulunber meadow steppe of China. Environ Res Lett 11:054004. https://doi.org/10.1088/1748-9326/11/5/054004

42. Yan RR, Tang HJ, Lv SH, Jin DY, Xin XP, Chen BR, Zhang BH, Yan YC, Wang X, Murray PJ, Yang GX, Xu LJ, Li LH, Zhao S (2017) Response of ecosystem $\mathrm{CO}_{2}$ fluxes to grazing intensities - a five-year experiment in the Hulunber meadow steppe of China. Sci Rep 7:9491.

https://doi.org/10.1038/s41598-017-09855-1

43. Yeates GW (2003) Nematodes as soil indicators: functional and biodiversity aspects. Biol Fert Soils 37:199-210. https://doi.org/10.1007/s00374-003-0586-5

44. Yeates GW, Bongers T, De Goede RGM, Freckman DW, Georgieva SS (1993) Feeding habits in soil nematode families and genera-an outline for soil ecologists. J Nematol 25:315-331. https://doi.org/10.0000/PMID19279775

45. Zhang X, Guan P, Wang Y, Li Q, Zhang S, Zhang Z, Bezemer TM, Liang W (2015) Community composition, diversity and metabolic footprints of soil nematodes in differently-aged temperate forests. Soil Biol Biochem 80:118-126. https://doi.org/10.1016/j.soilbio.2014.10.003

46. Zolda $P$ (2006) Nematode communities of grazed and ungrazed semi-natural steppe grasslands in Eastern Austria. Pedobiologia 50:11-22. https://doi.org/10.1016/j.pedobi.2005.08.002

\section{Figures}




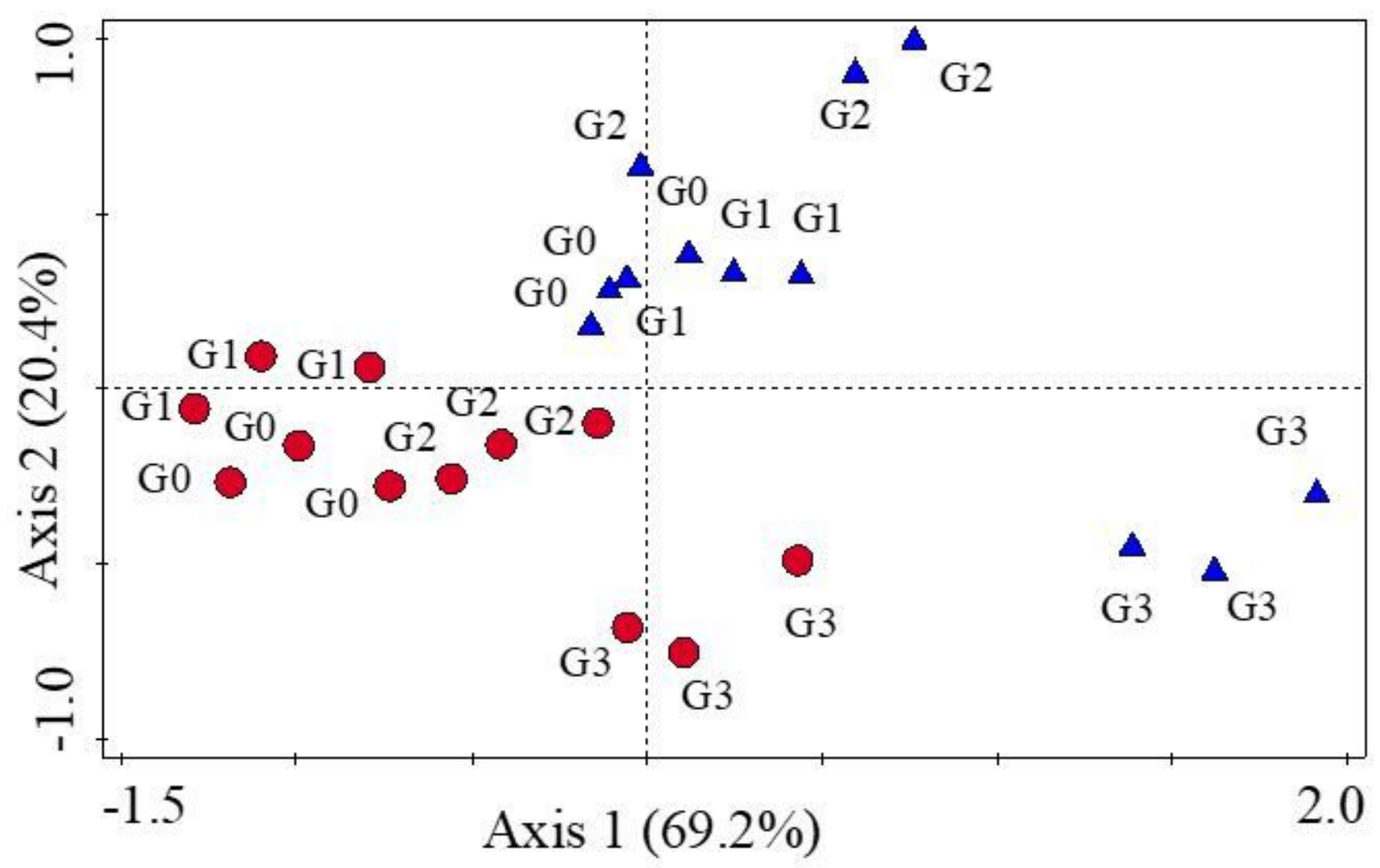

Figure 1

Non-metric multi-dimensional scaling (NMDS) plot in light of genera of soil nematodes among different soil layers. Grazing intensities G0, G1, G2 and G3 indicate $0.00,0.23,0.46$ and 0.92 AU ha- 1 respectively. Soil samples of $0-10 \mathrm{~cm}$ and $10-20 \mathrm{~cm}$ soil layers were presented by red circles and blue triangles, respectively 


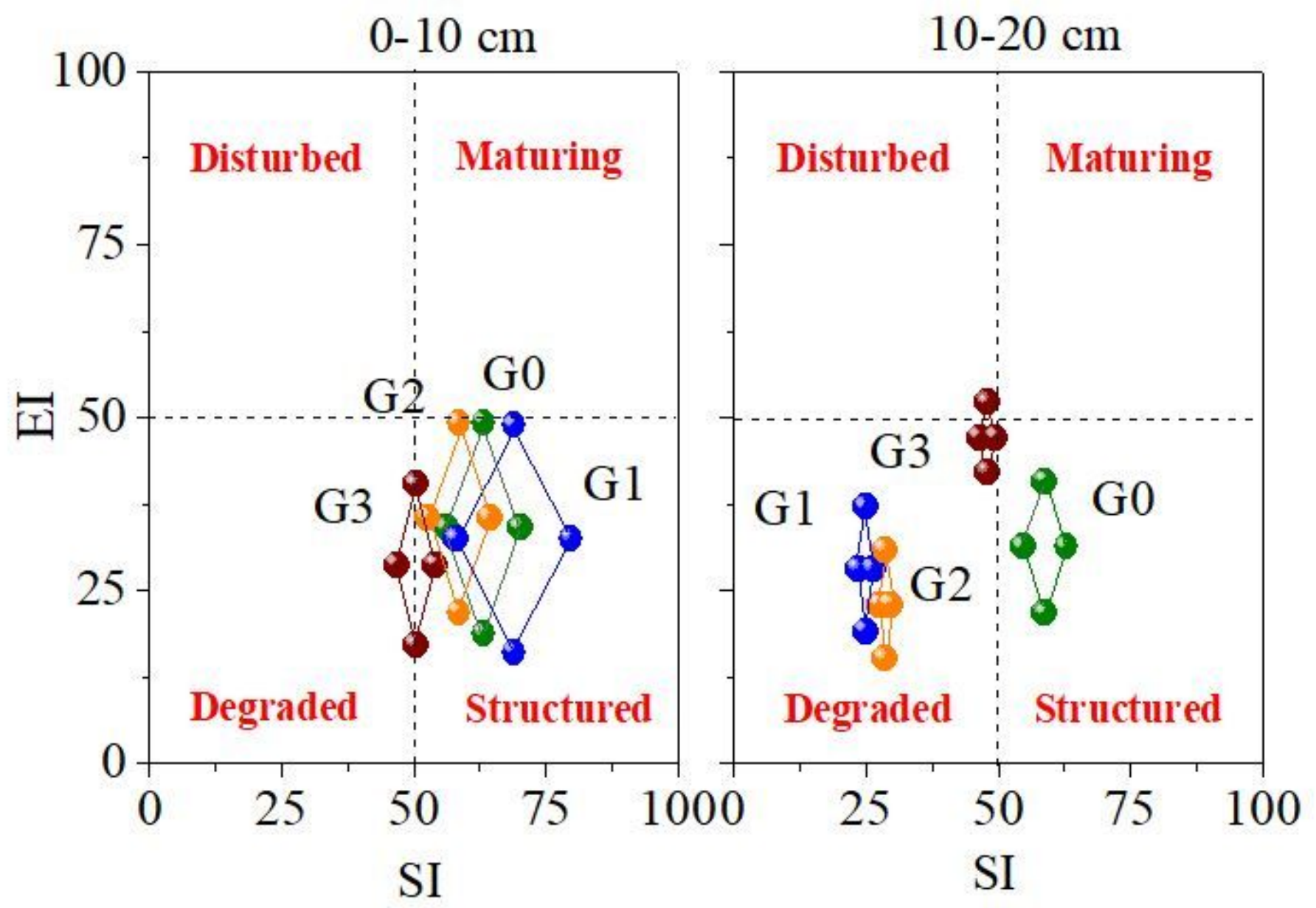

Figure 2

Functional metabolic footprint of soil nematodes in different grazing treatments. El, enrichment index, SI, structure index. The area enclosed by the four connected symbols for each grazing intensity indicates the functional footprints of soil nematodes. Grazing intensities G0, G1, G2 and G3 indicate $0.00,0.23,0.46$ and 0.92 AU ha-1 respectively. G0 - green; G1 - blue; G2 - orange; G3 - brown 

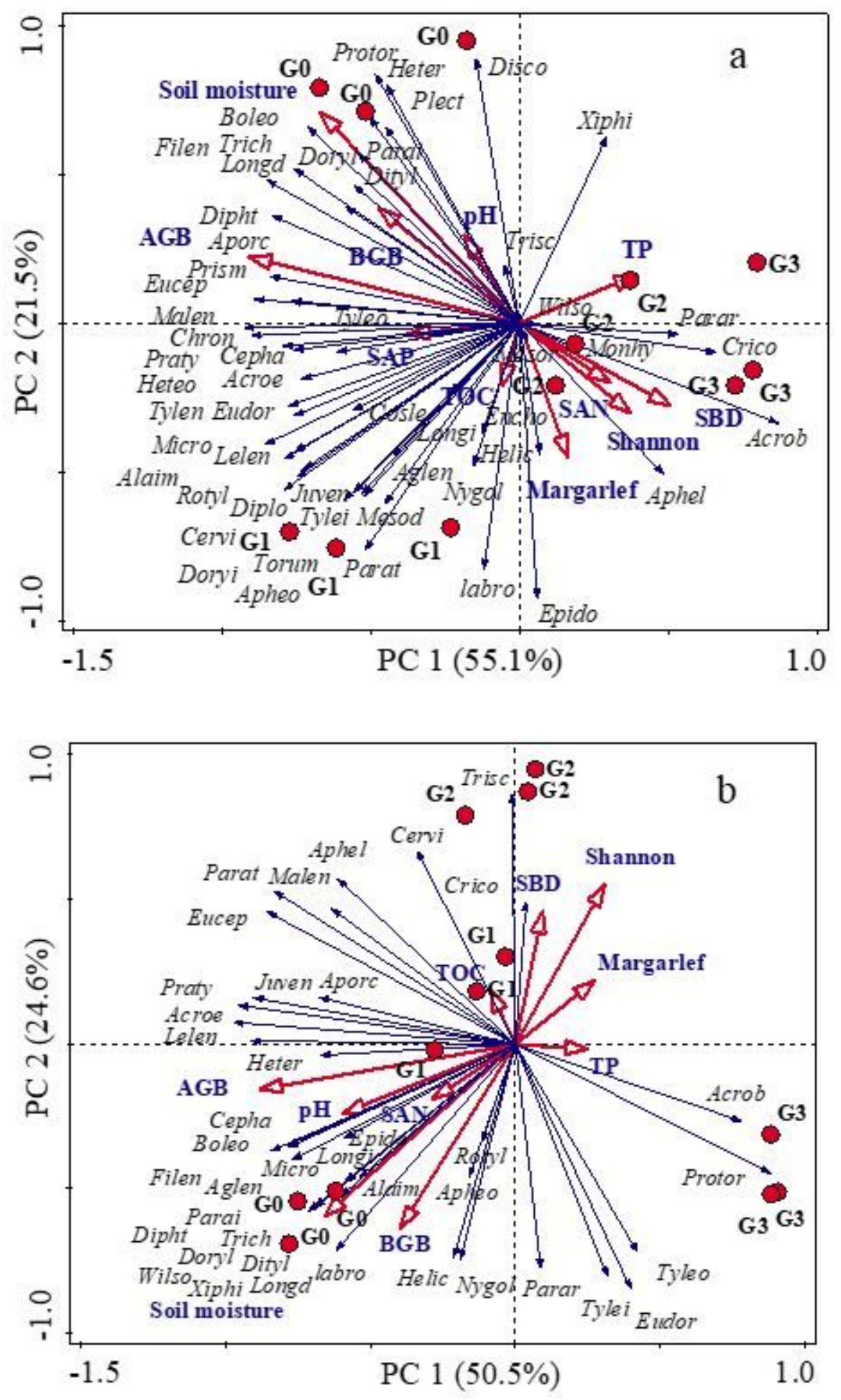

\section{Figure 3}

Correlation biplot of PCA based on soil nematode genera and environmental parameters of the $0-10 \mathrm{~cm}$ (a) and $10-20 \mathrm{~cm}$ (b) soil layers. The full names of the nematode genera are listed in supplementary Table 1. Grazing intensities G0, G1, G2 and G3 indicate $0.00,0.23,0.46$ and 0.92 AU ha-1 respectively. TOC, soil organic carbon; TP, total phosphorus; SAN, soil available nitrogen; SAP, soil available 
phosphorus; AGB, aboveground biomass of grass; BGB, belowground biomass of grass; SBD, soil bulk density; Margarlef, Margarlef index of grass; Shannon, Shannon diversity of grass
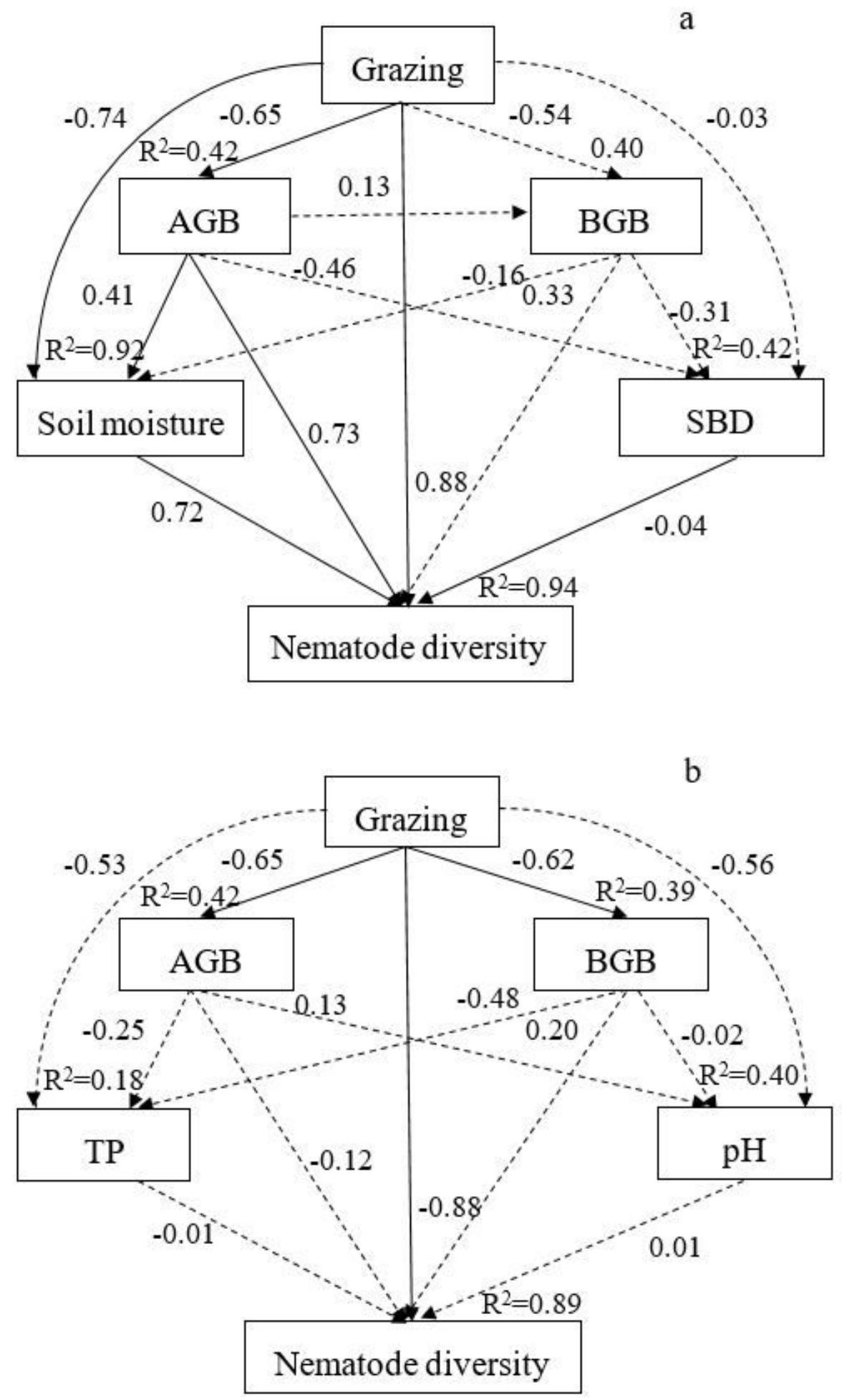

Figure 4

Structural equation modelling (SEM) analysis of the effects of grazing on soil nematode abundance in the $0-10 \mathrm{~cm}$ soil layer (a) (Chi-square $=0.31$, probability level $=0.58, \mathrm{AIC}=52.31$ ) and the $10-20 \mathrm{~cm}$ soil layer $(\mathrm{b})$ (Chi-square $=0.37$, probability level $=0.83, \mathrm{AIC}=50.37$ ). AGB, aboveground biomass of grass; 
BGB, belowground biomass of grass; SBD, soil bulk density; moisture, soil moisture; TP, total soil phosphorus; TOC, total soil organic carbon. Solid arrows represent significant effects $(p<0.05)$; dashed arrows represent significant effects and nonsignificant effects $(p>0.05)$. R2 values indicate the proportion of response variation explained by relationships with other variables. Values associated with arrows indicate standardized path coefficients

\section{Supplementary Files}

This is a list of supplementary files associated with this preprint. Click to download.

- SupplementaryTable1.docx 